\title{
Use of complementary treatment by those hospitalised with acute illness
}

\author{
Jeremy Armishaw, Cameron C Grant
}

\begin{abstract}
Aim-To determine the frequency of use of complementary treatment and measure its impact on clinical outcomes in a hospitalised general paediatric population.

Methods-A population based random sample of children admitted to the general paediatric service at a metropolitan children's hospital in Auckland, New Zealand from February to July 1998. Children with asthma, pneumonia, bronchiolitis, gastroenteritis, or fever were eligible. Data collected by personal interview with parents and by review of the medical records of these children.
\end{abstract}

Results-251 of 511 eligible children admitted during the study period were enrolled. Forty four children (18\%) had received complementary treatment during the hospitalising illness. Most children $(77 \%)$ had been seen in primary care before hospitalisation. The proportion that were seen in primary care and the number of primary care visits before hospitalisation did not vary with receipt of complementary treatment. The proportion of children who were prescribed medications before hospitalisation was significantly greater for those who had received complementary treatment compared with those who had not $(59 \% v 39 \%)$. There was no significant difference between users and non-users of complementary treatment in the severity of the illness at presentation, investigations performed, treatment administered, or length of inpatient stay.

Conclusion-A substantial proportion of children hospitalised with acute medical illnesses have received complementary treatment. Alternative health care is used as an adjunct rather than an alternative to conventional health care. Receipt of complementary treatment has no significant effect on clinical outcomes for children hospitalised with common acute medical illnesses.

(Arch Dis Child 1999;81:133-137)

Keywords: complementary treatment; acute medical illness; hospitalisation; ethnicity

Correspondence to: Dr C Grant, Department of Paediatrics, Faculty of

Medicine and Health

Sciences, The University of

Auckland, Private Bag

92019, Auckland 1,

New Zealand.

email: cc.grant@

auckland.ac.nz

Accepted 17 March 1999 heterogeneous set of practices which are ventional medicine for the preservation of offered as an alternative or an addition to con- health and the diagnosis and treatment of health related problems". ${ }^{1}$

There is no doubt from the literature that the use of such treatment is widespread. Australians spent Au $\$ 1$ billion on complementary treatment in 1993. In comparison, during the same year, only Au $\$ 360$ million was spent on patient contributions to all classes of pharmaceutical drugs. ${ }^{2}$ In the USA in 1990, about US $\$ 13.7$ billion was spent on complementary treatment. $^{3}$

Recent publications indicate that complementary treatment is frequently sought by parents of children with chronic illnesses. Fifty five per cent of Australian children with asthma ${ }^{4}$ and $46 \%$ of children with cancer received alternative treatments in studies on children seen in tertiary referral clinics. ${ }^{5}$ A recent Canadian study showed that $70 \%$ of children with chronic juvenile arthritis were receiving complementary treatment. ${ }^{6}$

The degree to which complementary treatment is given to children with common acute illness is less well described. Eleven per cent (208 of 1911) of children attending a general paediatric clinic in Quebec were reported to have used one or more form of complementary treatment since birth. Respiratory, ear, nose, throat, and musculoskeletal symptoms were the reasons given for most children receiving these forms of treatment. ${ }^{7}$

The aim of our study was to quantify the frequency of receipt of complementary treatment by children hospitalised with common acute medical illnesses. We also sought to measure the impact of the receipt of such treatment on clinical outcomes for these children.

\section{Methods}

This was a population based study of children aged 0-14 years admitted to the Starship Children's Hospital with common acute medical illnesses. We included children with an admitting diagnosis of asthma, pneumonia, bronchiolitis, gastroenteritis, or fever. Only children resident in the areas of metropolitan Auckland for which Starship is the secondary health care provider were eligible.

This hospital is the sole secondary care provider for a metropolitan population of 136263 children aged $0-14$ years. $^{8}$ Of these 136263 children, 64\% (86 666) are European, 15\% (20 440) Maori, 14\% (19 077) Pacificans, and $7 \%$ (10 080) are of other ethnicities. ${ }^{9}$

From 10 February 1998 to 17 July 1998 eligible patients were randomly selected from lists of the previous day's admissions. We selected two children each day from the patient admission list using each child's national health 
information number and a random numbers table. If a parent refused or could not be interviewed because English was not one of his/her spoken languages a replacement child from the day's admission list was sought. We aimed to enrol 250 children.

Written informed consent was obtained from each child's parent(s). After completion of the consent process parents were interviewed using a structured questionnaire. All interviews were conducted by one of the investigators (JA). Where necessary, an interpreter was used to assist families with informed consent and with the completion of the interview.

The questionnaire collected information that described the use of health care and treatment during the illness that resulted in hospitalisation. In particular, data were collected on the use of conventional health care and complementary treatment, the number of family practitioner/after hours doctor visits, the number of prescriptions filled, and the type of complementary treatment practitioners/ modalities sought in the current illness.

A chart review was performed on all enrolled patients. Data were extracted from the clinical notes on variables that described the severity of illness at hospital presentation, the investigations performed, treatment given, and length of inpatient stay. Severity of illness measures used were heart rate, respiratory rate, haemoglobin oxygen saturation, and temperature at presentation; and the number of hours that the heart rate and respiratory rate were raised above published age appropriate upper limits. ${ }^{10}$

The investigations performed during each child's hospital stay were abstracted from the medical chart and checked against the hospital laboratory's computerised record for each patient. The current charge for each radiological and laboratory investigation was obtained from the hospital financial management services. Inpatient investigations on each child in the complementary treatment and noncomplementary treatment groups were compared by summing the charges made for each laboratory and radiological test for each child.

For each child we recorded whether oxygen, intravenous fluids, nebulised bronchodilators, or intravenous antibiotics were given. We recorded the number of hours that oxygen and intravenous fluids were given, the number of nebulisations, and the number of doses of intravenous antibiotics.

Data were double entered into an Excel spreadsheet and then imported into SAS. Statistical analysis was conducted using SAS/PC version 6.12 software. ${ }^{11}$ Frequency distributions and plots were examined for the independent variables. Proportions were compared using the $\chi^{2}$ test. Non-normally distributed continuous variables were compared using the Wilcoxon rank sum test. Normally distributed continuous variables were compared using the $t$ test.

Ethical approval for the study was obtained from the regional health authority. The Starship Maori and Pacific family support groups
Table 1 Comparison of eligible children enrolled and not enrolled

\begin{tabular}{lcll}
\hline & $\begin{array}{l}\text { Enrolled } \\
(n=251)\end{array}$ & $\begin{array}{l}\text { Not enrolled } \\
(n=260)\end{array}$ & p Value \\
\hline Age (years) & $1.9(0.6$ to 4.2$)$ & $1.9(0.6$ to 5.1) & 0.66 \\
Diagnosis (n (\%)) & $55(22)$ & $48(18)$ & \\
$\quad$ Asthma & $38(15)$ & $34(13)$ & \\
Pneumonia & $23(9)$ & $32(12)$ & \\
Bronchiolitis & $28(11)$ & \\
Gastroenteritis & $30(12)$ & $118(45)$ & 0.58 \\
Fever & $105(42)$ & & \\
Ethnicity (n (\%)) & & $112(43)$ & \\
European & $109(43)$ & $44(17)$ & \\
Maori & $47(19)$ & $78(30)$ & 0.93 \\
Pacific & $72(29)$ & $26(10)$ & \\
Other & $23(9)$ & & \\
\hline
\end{tabular}

^Median (interquartile range).

assisted in the development of the study protocol and facilitated the use of interpreting services.

\section{Results}

Two hundred and fifty one of 511 eligible children admitted during the study period were randomly selected and enrolled. Thirteen children who were originally selected could not be enrolled and were replaced. The reasons for non-enrolment were parental refusal $(n=1)$ and because either an interpreter or a parent was not available before the child's discharge from hospital $(n=12)$. There were no differences between age, presenting diagnosis, or ethnicity of those children enrolled and those not enrolled (table 1).

Eighteen per cent (44 of 251) of children had received complementary treatment during the illness that resulted in admission. Twenty nine per cent (72 of 251) of children had received complementary treatment at some point in their lives.

There was no significant difference between ethnic groups (European, Maori, Pacific, and others) in the frequency of use of complementary treatment during the hospitalising illness. However, Pacific children (35 of 72) were more likely to have ever received complementary treatment compared with Maori (10 of 47), European (22 of 109), and other ethnic groups (5 of 23$)\left(\chi_{3}^{2}=19.6 ; p=0.0002\right.$; table 2$)$.

The type of complementary treatment used varied with ethnicity. Homeopathy (6 of 16), naturopathy (6 of 16), chiropractory (3 of 16), and aromatherapy ( 1 of 16) were the forms of complementary treatment chosen by European children. Homeopathy (3 of 6), naturopathy (2 of 6), and spiritual healing ( 1 of 6 ) were the choices for Maori children. Pacific children were treated exclusively by Pacific Island healers: massage with oils alone (15 of 19), and herbal remedies (3 of 19), with one child receiving both forms of treatment. Of the three

Table 2 Use of complementary treatment by ethnic group

\begin{tabular}{lrrr}
\hline & \multicolumn{2}{c}{ Use of complementary treatment } & \\
\cline { 2 - 3 } Ethnic group & In current illness & Ever in life & Total \\
\hline European & $16(15)$ & $22(20)$ & 109 \\
Maori & $6(13)$ & $10(21)$ & 47 \\
Pacific & $19(26)$ & $35(49)$ & 72 \\
Other & $3(13)$ & $5(22)$ & 23 \\
Total & $44(18)$ & $72(29)$ & 251 \\
\hline
\end{tabular}


Table 3 Demography of children by use of complementary treatment (CT) during the acute illness

\begin{tabular}{|c|c|c|c|}
\hline & $\begin{array}{l}\text { CT users } \\
(n=44)\end{array}$ & $\begin{array}{l}\text { Non-CT users } \\
(n=207)\end{array}$ & $p$ Value \\
\hline Age $(\text { years })^{\star}$ & $2.1(0.9$ to 5.2$)$ & $1.8(0.6$ to 4.2$)$ & 0.22 \\
\hline Sex (\% boys) & 57 & 49 & 0.31 \\
\hline Ethnicity (\%) & & & 0.13 \\
\hline European & 36 & 45 & \\
\hline Maori & 14 & 20 & \\
\hline Pacific & 43 & 26 & \\
\hline Other & 7 & 9 & \\
\hline \multicolumn{4}{|c|}{ Diagnosis (\% of total) } \\
\hline Asthma & 16 & 23 & 0.29 \\
\hline Pneumonia & 23 & 13 & \\
\hline Bronchiolitis & 4 & 10 & \\
\hline Gastroenteritis & 9 & 13 & \\
\hline Fever & 48 & 41 & 0.29 \\
\hline \multicolumn{4}{|c|}{ Referred from primary } \\
\hline health care $(\%)$ & 50 & 50 & 0.97 \\
\hline
\end{tabular}

children of other ethnicities who received complementary treatment, one was treated with homeopathy, one with acupuncture, and one consulted a Chinese herbalist.

Children who had received complementary treatment during their hospitalising illness were no different from those who had not when comparisons were made of their age, sex, ethnicity, diagnosis, and referral (table 3). The proportion of children who had seen their primary care provider during the acute illness did not differ between those who had compared with those who had not received complementary treatment $\left(55 \%\right.$ v $46 \% ; \chi_{1}^{2}=1.09$; $\mathrm{p}=0.30)$. Children who had seen their primary care provider made between one and three visits if they had received complementary treatment and between one and five visits if they had not received it. The proportion who made one, two, or three or more visits was not different for those who had compared with those who had not received complementary treatment $\left(\chi_{2}^{2}=0.59 ; \mathrm{p}=0.74\right)$.

Table 4 Severity of illness at presentation by receipt of complementary treatment $(C T)$ during the acute illness

\begin{tabular}{|c|c|c|c|}
\hline & CT Users $(n=44)$ & Non-CT users $(n=207)$ & $p$ Value \\
\hline Nurse triage score $(\% \leqslant 3)$ & 46 & 53 & 0.38 \\
\hline \multicolumn{4}{|l|}{ Maximum heart rate (HR) } \\
\hline (beats/min) & $155(145$ to 165$)$ & $162(158$ to 166$)$ & 0.62 \\
\hline Hours HR $>98^{\text {th }} \%$ & $2.4(0$ to 9$)$ & $2.6(0$ to 9$)$ & 0.78 \\
\hline \multicolumn{4}{|l|}{ Maximum respiratory rate (RR) } \\
\hline (breaths $/ \mathrm{min}$ ) & $38(28$ to 48$)$ & $44(32$ to 56$)$ & 0.09 \\
\hline Hours RR $>98^{\text {tho }} \%$ & $2.5(0$ to 14$)$ & $3.3(0$ to 14$)$ & 0.91 \\
\hline Maximum temperature $\left({ }^{\circ} \mathrm{C}\right)$ & $38.3(37.1$ to 38.9$)$ & $37.6(36.9$ to 38.6$)$ & 0.52 \\
\hline
\end{tabular}

Nurse triage score is a five point rating scale indicating those most urgent of medical attention: 1 , see immediately; 2 , see within 10 minutes; 3 , see within 30 minutes; 4 , see within one hour; 5 , see within two hours.

Maximum HR expressed as mean (95\% confidence intervals).

Other variables expressed as median (interquartile range).

Table 5 Intensity of inpatient treatment by receipt of complementary treatment (CT) during the acute illness

\begin{tabular}{llll}
\hline & CT users $(n=44)$ & Non-CT users $(n=207)$ & $p$ Value \\
\hline $\mathrm{O}_{2}$ (\% requiring) & 25 & 15 \\
$\mathrm{O}_{2}$ (hours received) & $33(19$ to 48$)$ & $23(11$ to 55$)$ & 0.69 \\
IV fluids (\% requiring) & 27 & 29 & \\
IV fluid (hours received) & $22(16$ to 37$)$ & $18(10$ to 37$)$ & 0.45 \\
Nebuliser (\% requiring) & 18 & 28 & 0.29 \\
Nebuliser (number of treatments) & $25(10$ to 53$)$ & $14(9$ to 23$)$ & 0.56 \\
IV antibiotic (\% requiring) & 66 & 53 & 0.19 \\
IV antibiotic doses & $8(5$ to 13$)$ & $8(5$ to 11$)$ & \\
Length of stay in hours & $54(25$ to 81$)$ & $44(26$ to 67$)$ & \\
\hline
\end{tabular}

Where appropriate variables are expressed as median (interquartile range). IV, intravenous.
The proportion of children who had seen an after hours primary care provider during the acute illness did not differ between those who had compared with those who had not received complementary treatment $\left(50 \%\right.$ v $44 \% ; \chi_{1}^{2}$ $=0.63 ; \mathrm{p}=0.43)$. Children who had seen an after hours provider made between one and five visits if they had received complementary treatment and between one and four visits if they had not received such treatment. The proportion who made one, or two or more visits was not different for those who had compared with those who had not received complementary treatment $\left(\chi_{1}^{2}=0.00 ; p=0.95\right)$. Seven per cent of children who had received complementary treatment and $11 \%$ of those who had not received it made a visit to a hospital emergency department before presentation for admission $\left(\chi_{1}^{2}=0.59 ; \mathrm{p}=0.44\right)$.

Seventy nine per cent of children who received complementary treatment and $76 \%$ of those who did not had been seen by their normal primary care provider, an after hours provider, or a hospital emergency department before hospitalisation. The proportion who made one, two, or three or more visits was not different for those who had compared with those who had not received complementary treatment $\left(\chi_{2}^{3}=0.71 ; \mathrm{p}=0.70\right)$.

The proportion of children who were prescribed medications before hospitalisation was significantly greater for those who had received complementary treatment compared with those who had not $(59 \%$ v 39\%; $\left.\chi_{1}^{2}=0.59 ; \mathrm{p}=0.013\right)$.

Approximately one half of the children in both groups had a nurse triage score indicating that they needed to be seen by a doctor within 30 minutes of arrival in the emergency department. There was no difference between the two groups in the maximum heart or respiratory rates in the emergency department or in the number of hours the heart rate and respiratory rate were raised (table 4).

Summation of the total cost of all investigative procedures was used to compare investigations performed on children during this admission. There was no difference between complementary treatment users and non-users ( $\$ 95 v \$ 76 ; \mathrm{p}=0.06$ ) when the mean cost of inpatient investigations performed was compared.

Table 5 summarises the conventional treatments that were received by the children enrolled in the study. The proportion of children receiving oxygen, intravenous fluids, and intravenous antibiotics, and the duration of treatment with each of these treatments was similar for children who had received complementary treatment compared with those who had not.

\section{Discussion}

Complementary treatment is received by a large proportion of children hospitalised in Auckland with common acute medical illnesses. Eighteen per cent of our sample used this treatment with their current illness, and $29 \%$ had used complementary treatment at some point in their lives. 
The frequency of complementary treatment use was less than in other reported studies of children. The mean age of the children using complementary treatment in our cohort was 2.9 years. This is a younger population than enrolled in the study of children with asthma (mean age, 3.9 years; complementary treatment use $55 \%$ ), ${ }^{4}$ cancer (mean age, 8.3 years; complementary treatment use $46 \%),{ }^{5}$ and chronic juvenile arthritis (mean age, 16 years; complementary treatment use $70 \%) .{ }^{6}$ It seems likely that the high use of complementary treatment in these studies relates to the chronicity of the subjects' illness more than the age of the subjects. In chronic illness a cure may be less immediately forthcoming with orthodox medicine, thus encouraging parents to shop around for a panacea for their child.

There was no significant difference between ethnic groups in the frequency of use of complementary treatment in the acute illness. However, Pacific children were significantly more likely to have used complementary treatment $(49 \%)$ at some point in their lives. Other investigators have similarly reported a high incidence of use of complementary treatment in Pacific children. Aiau ${ }^{12}$ interviewed 24 Samoan families with children admitted to a general paediatric ward in a metropolitan New Zealand hospital. Seventy nine per cent had received massage and $33 \%$ had been treated with Samoan herbal remedies at some point in their lives. Only 13\% of these children had not received any traditional Samoan healing. Certain cultural beliefs may contribute to this. In Samoa, health care is not provided by a family doctor but is managed by a healer (Fofo) or if necessary a visit to the district hospital. Similarly, distinctions are often drawn between ma'i Samoa (illness particular to Samoans) and ma'i Palagi (illnesses of Europeans). If it is decided that the child is afflicted with ma'i Samoa, Western medicine will be ineffective and hence a Fofo must be sort. ${ }^{12}$

A key motivation in the design of our study was to evaluate whether children admitted to our service might be disadvantaged by the use of complementary treatment. Could this treatment cause harm through inherent toxicity? Most authors regard such treatments as relatively safe and harmless, ${ }^{13}$ although case reports exist of remedies causing direct toxicity. ${ }^{1415}$

It would be narrow minded to disregard complementary treatment as having no clinical benefit. Even if no efficacy is demonstrable at the molecular level, considerable placebo benefit may still be derived. Some unorthodox remedies have been found to be beneficial in double blind placebo controlled trials. ${ }^{16}$ It is worth remembering that the efficacy of many orthodox treatments have not been demonstrated in well designed clinical trials.

Most proponents of orthodox medicine would agree that if complementary treatment is to be accepted it must be supported by impartial scientific evidence of benefit and also be accompanied by a plausible mechanism of action..$^{13}$ Nevertheless, it is worth noting that it is only in the past century that orthodox prac- titioners have had more than just their bedside manner to offer ill patients, ${ }^{13}$ and that many remedies adopted by orthodox practitioners were first prescribed by so called charlatans (such as digoxin, opium derivatives, and salicylates). ${ }^{1}$

Seeking complementary treatment for children could potentially cause serious harm by delaying or preventing the use of orthodox medical care for those with a potentially severe illness. Our study has shown that complementary treatment is used as an adjunct to orthodox medicine rather than an alternative. Children receiving complementary treatment visit the family practitioner/after hours doctor during the acute illness as frequently as those children treated exclusively with orthodox medicine. The severity of illness on presentation to the hospital is unaffected by previous receipt of complementary treatment. Eisenberg concluded that it is rare for unconventional treatment to be used for serious illness in the absence of contact with a medical doctor. ${ }^{3}$ Our findings indicate that this is the manner in which complementary treatment is used for children with acute illnesses requiring hospitalisation.

Complementary treatment users filled significantly more prescriptions during the hospitalising illness. Perhaps parents of children receiving complementary treatment are more motivated to find a cure for their child's ailment and as a consequence more willing to accept and fill a doctor's prescription. Other authors have similarly concluded that, in general, complementary treatment is used as an adjunct to conventional care rather than as a replacement for it. ${ }^{3} 1317$

A median of $\$ 95$ was spend on laboratory and radiological investigations of children who had received complementary treatment compared with $\$ 76$ on those who had not received it. Although this comparison approached significance, the absence of any association between the use of complementary treatment and the frequency or duration of administration of $\mathrm{O}_{2}$, intravenous fluids, intravenous antibiotics, or nebulised bronchodilators implies that the receipt of complementary treatment does not result in any change in the intensity of services required for an episode of acute illness.

There is evidence in the literature that patients of every social, economic, and educational class seek and use complementary treatment. ${ }^{1}$ Maddocks ${ }^{18}$ commented: "Alternative practice is an embarrassment to modern medicine. We are confused about whether to reject it, ignore it, or employ it more often." Our findings indicate that a more moderate stance is appropriate.

Therefore, we suggest that the ideal practice should be to enquire about the use of complementary treatment for all children we see. We should do this in a non-judgmental fashion and in a manner that does not denigrate the parents' genuine efforts to seek help for their sick children. This is especially important when conventional medicine does not always hold immediate cures. ${ }^{13}$ Only when parents feel comfortable about entering into dialogue with 
orthodox practitioners about the use of complementary treatment will we be able to identify those treatments and beliefs that are harmful or, alternatively, those that are potentially beneficial and should be adopted as conventional treatments.

This research was funded in part by a grant from the Auckland Savings Bank.

1 Murray HR, Rubel AJ. Physicians and healers-unwitting partners in health care. N Engl f Med 1992;326:61-4.

2 MacLennan AH, Wilson DH, Taylor AW. Prevalence and cost of alternative medicine in Australia. Lancet 1996;347: 569-73.

3 Eisenberg DM, Kessler RC, Foster C, Norlock FE, Calkins DR, Delbanco TL. Unconventional medicine in the United States: prevalence, costs and patterns of use. N Engl F Med

4 Andrews L, Lokuge S, Sawyer M, Lillywhite L, Kennedy D, Martin J. The use of alternative therapies by children with asthma: a brief report. F Paediatr Child Health 1998;34:31-4

5 Sawyer MG, Gannoni AF, Toogood IR, Antoniou G, Rice $M$. Children with cancer, the use of alternative therapies by children with cancer. Med f A ust 1994;160:320-4.

6 Southwood TR, Malleson PN, Roberts-Thomson PJ, Mahy M. Unconventional remedies used for patients with juvenile arthritis. Paediatrics 1990;85:150-3.
7 Spigelbatt L, Laine-Ammara G, Pless B, Guyver A. The use of alternative medicine by children. Paediatrics 1994;94: 811-14.

8 New Zealand census of population and dwellings: Northland/ Auckland regional report. Wellington: Department of Statistics, 1992.

9 Walker R. The people in the North Health Region. Client relations and research. Auckland: North Regional Health Authority, 1993.

10 Barone MA, ed. The Harriet Lane handbook, 14th ed. St Louis: Mosby-Year Book Inc, 1996.

11 SAS Institute Inc. SAS/STAT statistics, version 6, 4th ed. Cary, NC: SAS Institute Inc, 1994.

12 Aiau C. Aspects of traditional healing in the Samoan paediatric population [dissertation, diploma of paediatrics]. Auckland: Auckland University, 1994.

13 Spigelblatt LS. Alternative medicine: should it be used by children? Curr Probl Pediatr 1995;25:180-8.

14 Toro T. Poisoning fears leads to German ban on herbal remedies. New Sci 1992;1831:10.

15 Perharic L, Shaw D, Murray V. Toxic effects of herbal medicines and food supplements. Lancet 1993;342:180-1.

16 Shipley M, Berry H, Broster G, Jenkins M, Clover A, Williams I. Controlled trial of homeopathic treatment of osteoarthritis. Lancet 1983;i:97-8.

17 Donnelly WJ, Spykerboer JE, Thong YH. Are patients who use alternative medicine dissatisfied with orthodox medicine? Med f Aust 1985;142:539-41.

18 Maddocks I. Alternative medicine. Med $\mathcal{F}$ Aust 1985;142: $547-51$. 